\title{
Spontaneous Spinal Epidural Haemorrhage During Anticoagulant Therapy*
}

\author{
I. JACOBSON, B.SC., F.R.C.S.ED. ; J. J. MACCABE, $\dagger$ M.B., CH.B., F.R.C.S.ED. \\ P. HARRIS, F.R.C.S.ED., F.R.C.P.ED., F.R.C.S.GLASG.; .N. M. DOTT, †.B.E., F.R.C.S.ED., F.R.S.ED.
}

Brit.med. F., 1966, 1, 522-523

Spinal epidural haemorrhage is a rare clinical entity, and the literature provides reports of fewer than 50 examples. Though occasionally attributed to the presence of a local vascular anomaly, in most cases the haemorrhage has been regarded as spontaneous; and its incidence was greatest in elderly and hypertensive subjects. Mild trauma has been considered to be a precipitating factor in some instances. In recent years concurrent anticoagulant therapy has also been suspected as a possible contributory factor. We report on three further examples.

\section{Case 1}

A 61-year-old housewife was admitted to hospital in July 1961 with an acute onset of interscapular tightness, pain radiating into both upper limbs, and paraesthesiae in the fingers. An episode of coronary ischaemia was suspected; the E.C.G. was normal. Neurologically she was intact at that stage. Anticoagulant therapy was begun and the prothrombin activity reduced to $50 \%$.

Three days later she developed severe nuchal pain, weakness of both upper limbs, and marked hypotension. The E.C.G. was again normal. Vasoconstrictor drugs were administered, and her blood-pressure was rapidly stabilized. However, the following day, over a period of some four hours, she became completely paraplegic, with a sensory level corresponding to the fourth thoracic segment. Clinically there was no evidence of excessive anticoagulant therapy.

Plain radiographs of the spine showed no abnormality; a lumbar puncture demonstrated a complete subarachnoid block; and a

- From the Department of Surgical Neurology, Western General Hospital and Royal Infirmary, Edinburgh.

† Now Consultant Neurosurgeon, King's College Hospital, Denmark Hill, London.

‡ Now Professor Emeritus, Neurological Surgery, University of Edinburgh.
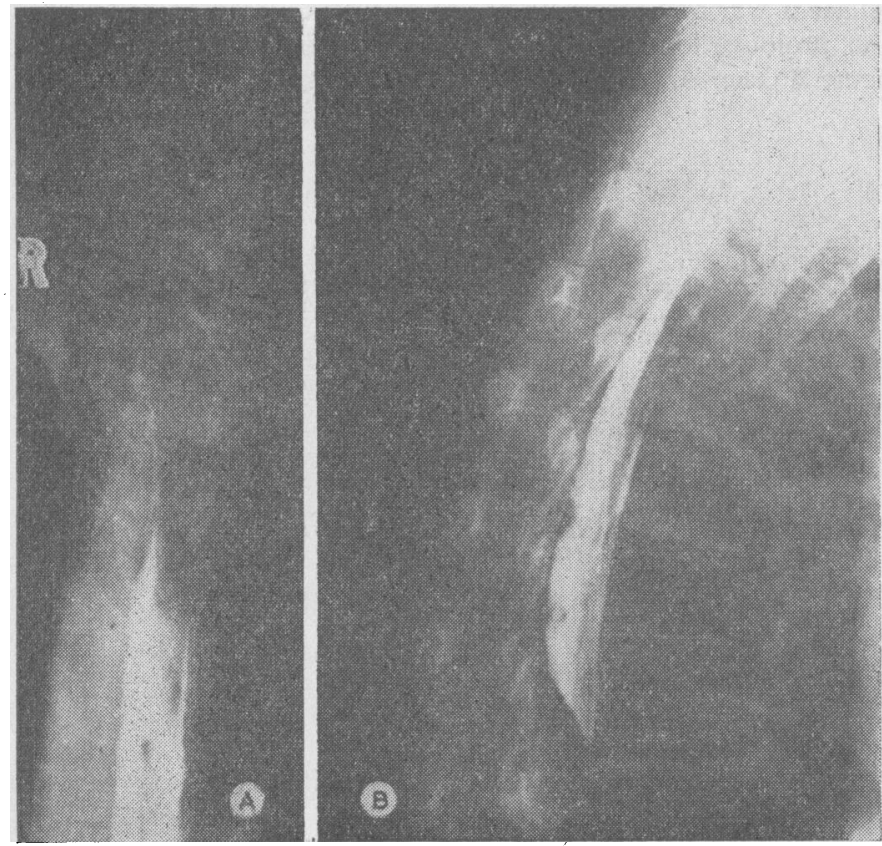

Fic. 1.-Case 1. Myelogram. A, Antero-posterior view. B, lateral view. myelogram (Fig. 1, A and B) showed evidence of an elongated extradural mass lying mainly anteriorly and to the left at the level of the fifth dorsal vertebra. The prothrombin activity was raised by means of intravenous vitamin $\mathrm{K}_{1}$. A laminectomy was performed 30 hours after the onset of symptoms and some seven hours after complete paraplegia was evidenced. A soft extradural haematoma extending from the second to the fourth thoracic vertebra was disclosed and removed. No intradural pathology was seen. Histological examination of the haematoma showed no evidence of a pre-existing vascular malformation. Though relief was afforded within 12 hours of the onset of paraparesis, recovery of spinal-cord function was slow; and almost three years later she was still mainly confined to a wheelchair.

\section{Case 2}

A 60-year-old housewife, known to be hypertensive, was placed on long-term anticoagulants after a retinal-vein thrombosis. Prothrombin activity was well controlled throughout at about $30 \%$ of normal. Six months later (March 1961) she developed an infection of the upper respiratory tract, and during an acute bout of coughing severe lumbar pain occurred, associated with paraesthesia and paresis of both lower limbs. Within 24 hours she had a complete paraplegia, with a sensory level corresponding to the twelfth dorsal segment. Blood-pressure was $230 / 130 \mathrm{~mm}$. $\mathrm{Hg}$, and there was a degree of left ventricular hypertrophy.

Plain radiographs of the spine showed no abnormality. Lumbar puncture revealed a complete block, and a myelogram (Fig. 2, A and $B$ ) indicated an extradural mass opposite the body of the twelfth dorsal vertebra. The prothrombin activity was increased by administration of intravenous vitamin $\mathbf{K}$. A laminectomy was carried out within 48 hours after the onset of symptoms, and 12 hours after paraplegia had become complete. A semisolid epidural haematoma covering the dorsal aspect of the theca from D 12 to

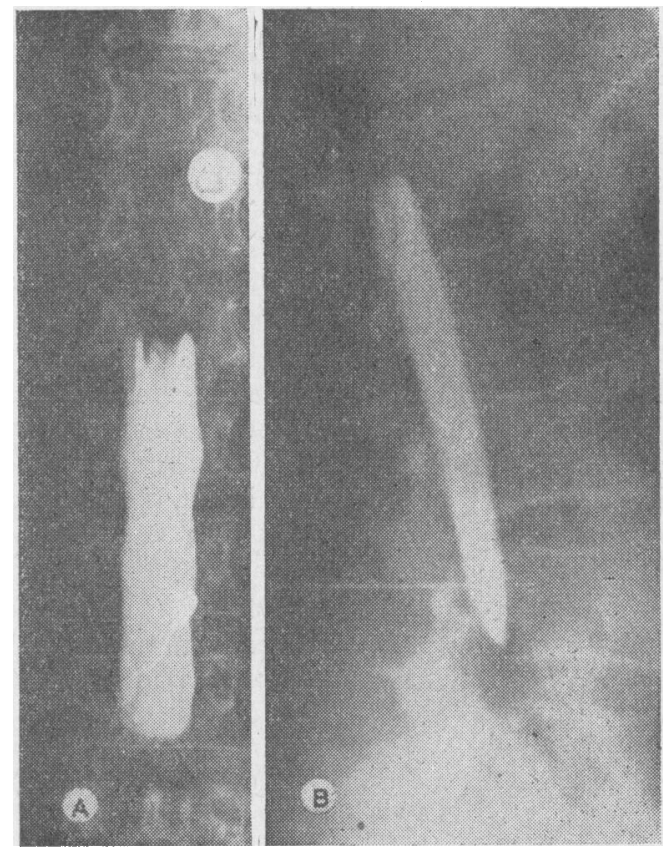

FIG. 2.-Case 2. Myelogram. A, Antero-posterior view. B, Lateral view. 
L 2 was encountered and removed. There was no intradural pathology. Recovery was protracted, but after six months she was fully ambulant but still with automatic bladder function. She now requires below-knee callipers, and has recovered bladder control.

\section{Case 3}

A 48-year-old plumber was established on long-term anticoagulant therapy after a myocardial infarct in 1960 . He was involved in a traffic accident in June 1962, but was uninjured. About three hours after this incident, while watching television, he felt unusually tired and noted slight neck discomfort. During the night this became more intense, and numbness and weakness of the upper limbs developed. Within the next 16 hours he became quadriplegic, with a sensory level corresponding to C 6-7 segment with, however, sacral sparing on the left.

Plain radiographs of the cervical spine revealed no evidence of injury. Minor osteophytosis was noted at C 4/5 level. Prothrombin activity was $35 \%$ of normal on admission and was increased with intravenous vitamin $\mathrm{K}$. A pre-operative diagnosis of an epidural haematoma was confirmed at a laminectomy of $\mathrm{C} 5$ and 6. A dark-red gelatinous haematoma some $10 \mathrm{~mm}$. thick was found lying mainly on the dorsal aspect of the theca. The haematoma was incised to ensure a dorsal decompression. Recovery was slow but eventually satisfactory. Six months after operation he was fully ambulant, with, however, a persistent weakness of the left hand. $\mathrm{He}$ died 11 months later from a further myocardial infarct.

\section{Discussion}

Perhaps the earliest record of spontaneous epidural haematoma was made by Jackson (1869). His patient, a 14year-old girl, developed a progressive quadriparesis and died of respiratory failure. A large cervical haematoma was found at necropsy. The correct clinical diagnosis in this case was made by Sir William Jenner. Sporadic reports of further cases have appeared since (Bain, 1897 ; Hopkins, 1899 ; Jonas, 1911 ; Reid and Kennedy, 1925 ; Hassin and Stone, 1935 ; Ver Brugghen, 1946 ; Svien, Adson, and Dodge, 1950 ; Nichols and Manganiello, 1956 ; Lin, 1961 ; Cube, 1962).

From a review of all the case reports the significant features appear to be as follows:

Age and sex are not important factors. Patients ranged from $1 \frac{1}{2}$ to 79 years, and sex ratio is probably $1: 1$. Any segments of the spine may be involved. In the vast majority the haematoma extended over three vertebrae. The haematoma probably has its origin in the epidural venous plexus, but the mechanism provoking haemorrhage is obscure. Minor trauma is reported by most authors; but in a number of instances no precipitating factor was found (Lougheed and Hoffman, 1960). A haematoma sufficient to cause neurological impairment is a very unusual complication of spinal surgery or severe spinal injury. Those cases in which epidural haemorrhage was associated with some arterial, venous, or capillary abnormality in the spinal epidural region should probably be classified as complications of vascular anomalies (Dawson, 1960).

Anticoagulant therapy has been associated with nearly $20 \%$ of instances. Devanney and Osher (1952) described the case of a 62-year-old man, on dicoumarol for acute thrombophlebitis, who developed a spontaneous onset of low back pain, sciatica, and paraparesis. A haematoma extending from $\mathrm{L} 2$ to 5 was evacuated, with a good clinical recovery. Arieff and Pyzik (1954) described a case of paraplegia associated with excess anticoagulants. Surgery was not undertaken, a clinical diagnosis of haematomyelia being made. The case described by Alderman (1956) also probably had had an excess of anticoagulants. Further examples of epidural haematomata complicating anticoagulant therapy have been documented (Cloward and Yuhl, 1955 : Winer, Horenstein, and Starr, 1959 ; Weigert, 1961).
In the first case that we report there is some doubt whether the initial symptoms were indeed due to cardiac ischaemia or to a truly spontaneous but minor spinal haemorrhage. There is, however, no doubt that anticoagulant therapy facilitated the major haemorrhage that caused paraplegia. In Case 2 the onset of bleeding was probably provoked by a bout of coughing, but here again the clotting defect was responsible for the continued bleeding that provoked paraplegia. Trauma probably, initiated a minor haemorrhage in Case 3 ; but this continued long enough to cause quadriplegia because of the anticoagulant therapy. We have no evidence that in these three patients an excess of anticoagulants was administered at any time.

Certain investigations in such patients may present diffculties. Lumbar puncture carries the risk of inducing further haemorrhage, as in the case reported by Lin (1961). Though no clear clinical syndrome emerges from a review of all reported episodes, the onset of backache, radicular pain, and rapidly progressive spinal neurological deficits in a patient on anticoagulant therapy should raise the suspicion of a spinal epidural haematoma. One may, in some patients, omit myelography and proceed to a laminectomy on clinical evidence only, under cover of vitamin $\mathrm{K}$ and with fresh blood available. Where surgical decompression has not been unduly delayed, recovery of neurological function has been satisfactory. Surgical relief should be regarded as an emergency procedure.

In view of the high incidence and morbidity of venous thrombosis in patients immobilized after spinal injury, anticoagulants have been advocated for them. Thus far no report has been published of spinal haemorrhage as a complication of such therapy.

Whether any of our patients would have developed a haematoma in the absence of anticoagulants is open to question. It is, however, difficult to avoid the conclusion that this therapy was at least an important contributory factor in the development of significant haemorrhage in each.of them. There are now enough reports to establish that spinal epidural haemorrhage is one of the more formidable and serious complications of anticoagulant therapy.

\section{Summary}

Three cases of spinal epidural haemorrhage associated with anticoagulant therapy are reported. All presented with pain and an acute paraparesis or quadriparesis. A review of the literature revealed no precise clinical syndrome. However, the onset of acute spinal neurological deficits in any patient on anticoagulants must raise the suspicion that a spinal epidural haemorrhage has occurred, in which event surgical decompression is mandatory.

\section{REFERENCES}

Alderman, D. B. (1956). New Engl. 7. Med., 255, 839.

Arieff, A. J., and Pyzik, S. W. (1954). Quart. Bull. Northw. Univ. med. Sch., 28, 221.

Bain, W. (1897). Brit. med. 7., 2, 455.

Cloward, R. B., and Yuhl, E. T. (1955). Neurology (Minneap.), 5, 600.

Cube, H. M. (1962). f. Neurosurg., 19, 171 .

Dawson, B. H. (1960). F. Neurol. Neurosurg. Psychiat., 23, 85.

Devanney, J. W., and Osher, D. (1952). Dis. nerv. Syst., 13, 53. Hassin, G. B., and Stone, T. T. (1935). Arch. Neurol. Psychiat. (Chic.),
34, 401.

Hopkins, S. D. (1899). N.Y. St. F. Med., 70, 296.

Jackson, R. (1869). Lancet, 2, 5.

Jonas, A. F. (1911). f. Amer. med. Ass., 57, 859.

Lin, T. H. (1961). F. int. Coll. Surg., 36, 742

Lougheed, W. M., and Hoffman, H. J. (1960). Neurology (Minneap.), $10,1059$.

Nichols, P., jun., and Manganiello, L. O. J. (1956). f. Neurosurg., 13, 638 .

Reid, J., and Kennedy, J. (1925). Brit. med. F., 2, 946.

Svien, H. J., Adson, A. W., and Dodge, H. W., jun. (1950). F. Neurosurg., 7, 587.

Ver Brugghen, A. (1946). Ann. Surg., 123, 154

Weigert, M. (1961). Nervenarzt, 32, 85. Winer, B. M., Horenstein, S., and Starr, A. M. (1959). Circulation, 19, 